\title{
Erratum to: Comparative in vitro inhibition of urinary tract pathogens by single- and multi-strain probiotics
}

\author{
C. M. C. Chapman - G. R. Gibson • \\ S. Todd $\cdot$ I. Rowland
}

Published online: 2 July 2013

(c) Springer-Verlag Berlin Heidelberg 2013

\section{Erratum to: Eur J Nutr}

\section{DOI 10.1007/s00394-013-0501-2}

In the original publication of the article, incorrect strain identifications were used. The corrected version should be as given below:

Probiotics used were L. acidophilus NCIMB 30184 (PXN 35), L. fermentum NCIMB 30226 (PXN 44), L. plantarum NCIMB 30187 (PXN 47), and L. rhamnosus NCIMB 30188 (PXN 54).

The online version of the original article can be found under doi:10.1007/s00394-013-0501-2.

C. M. C. Chapman $(\bowtie) \cdot$ G. R. Gibson · I. Rowland Department of Food and Nutritional Sciences, University of Reading, P.O. Box 226, Whiteknights, Reading RG6 6AP, UK

e-mail: cb010202@reading.ac.uk

S. Todd

Department of Mathematics and Statistics,

University of Reading, P.O. Box 220, Whiteknights,

Reading RG6 6AX, UK 